\title{
High Magnetic Fields
}

Science and Technology 
This page is intentionally left blank

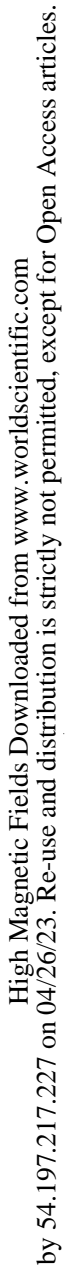


High Magnetic Fields

\section{Science and Technology}

\section{Theory and Experiments II}

editors

Fritz Herlach

Laboratorium voor Vaste-Stoffysika en Magnetisme, Katholieke Universiteit Leuven, Belgium

\section{Noboru Miura}

Institute for Solid State Physics, University of Tokyo, Japan 
Published by

World Scientific Publishing Co. Pte. Ltd.

5 Toh Tuck Link, Singapore 596224

USA office: 27 Warren Street, Suite 401-402, Hackensack, NJ 07601

$U K$ office: 57 Shelton Street, Covent Garden, London WC2H 9HE

\section{British Library Cataloguing-in-Publication Data}

A catalogue record for this book is available from the British Library.

\section{HIGH MAGNETIC FIELDS: SCIENCE AND TECHNOLOGY (Vol. 3)}

Copyright (C) 2006 by World Scientific Publishing Co. Pte. Ltd.

All rights reserved. This book, or parts thereof, may not be reproduced in any form or by any means, electronic or mechanical, including photocopying, recording or any information storage and retrieval system now known or to be invented, without written permission from the Publisher.

For photocopying of material in this volume, please pay a copying fee through the Copyright Clearance Center, Inc., 222 Rosewood Drive, Danvers, MA 01923, USA. In this case permission to photocopy is not required from the publisher.

ISBN $981-02-4964-0($ Vol. 1)

ISBN 981-02-4965-9 (Vol. 2)

ISBN 981-02-4966-7 (Vol. 3)

ISBN 981-02-4698-6 (Set) 


\section{CONTENTS}

Preface

Quasi-One-Dimensional Organic Conductors in High Magnetic Fields

J.S. Brooks and O.H. Chung

Flatland Electrons in High Magnetic Fields

M. Shayegan

Cyclotron Resonance in High Magnetic Fields

J. Kono and N. Miura

High $T_{c}$ Superconductors in Pulsed Magnetic Fields

J. Vanacken, V.V. Moshchalkov and F. Herlach

Field-Induced Magnetic Phase Transitions

125

K. Kindo, M. Motokawa and F.R. de Boer

Permanent Magnetism

K.-H. Müller, G. Fuchs and O. Gutfleisch

W.G. Moulton and A.P. Reyes

Biological Systems in High Magnetic Fields

W.R. Hagen

Plasmas and Megagauss Fields

P.J. Turchi

Magnetic Fields of White Dwarfs and Neutron Stars

$J$. Trümper, H. Ruder and M. Klews

Appendix: Update on Magnet Laboratory Addresses, Listing of High Magnetic

Field Conferences 
This page is intentionally left blank

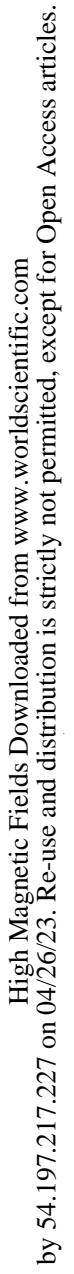




\section{PREFACE}

The magnetic field is a basic research tool in physics, with most applications in solidstate physics. Apart from the exciting aspect of advancing into uncharted territory where new effects are waiting to be discovered, higher fields provide both increased resolution and sensitivity. The Physics Nobel Prize for the discovery of the quantum fluid in high magnetic fields by Laughlin, Störmer and Tsui is one of the recent highlights. "Very high fields" are loosely defined as requiring special and some very large magnet laboratory facilities. Since the last comprehensive book on experiments with high magnetic fields was published in 1985 (Strong and Ultrastrong Magnetic Fields and Their Applications, ed. F. Herlach, Springer Topics in Applied Physics), very substantial progress has been made in magnet technology and experimental methods, and a wealth of experimental results has been accumulated. This is reflected in the size of the present survey that consists of three volumes, one on magnet technology, facilities and experimental techniques, and two on experiments and theory of physics and related topics in high magnetic fields.

In magnet technology, $33 \mathrm{~T}$ water-cooled magnets and a $45 \mathrm{~T}$ hybrid magnet have become operational at the U.S. National High Magnetic Field Laboratory at Tallahassee, and the new Nijmegen magnet laboratory is now in operation. Several new laboratories with pulsed magnets have been established, and existing laboratories have been upgraded and modernised. The level of non-destructive "user" fields has been raised from 50 to $70 \mathrm{~T}$, and $80 \mathrm{~T}$ is becoming available as the result of a European co-operative project. The HLD at Dresden is nearing completion, adding a new dimension to pulsed field laboratories. Several single-turn coil installations have been built at Tokyo and Berlin that provide fields up to $300 \mathrm{~T}$, and in electromagnetic compression it has recently become possible to generate $600 \mathrm{~T}$ reproducibly (at the University of Tokyo). Fields up to $1000 \mathrm{~T}$ from explosive-driven flux compression have become available at Sarov (Russia) and Los Alamos (partner of NHMFL). For pulsed magnetic fields in particular, new experimental techniques have been developed with unprecedented resolution and sensitivity, enabling experiments that two decades ago would have been considered a remote dream.

The present volume contains a chapter on organic conductors that is complementary to that in Vol. 2. Another complementary chapter is that on high temperature superconductors, where pulsed magnets provide an opportunity to finally resolve the puzzle of the mechanism that leads to high $T_{c}$ superconductivity. In addition to those in Vol. 2, there is another chapter on magnetic interactions, and one on permanent magnetism. Magnetism is a very wide field with a long tradition in high-field research and with large-scale practical applications. Two chapters cover different aspects of semiconductor physics, one on two-dimensional systems and one on cyclotron resonance. These confirm that semiconductor physics is still in the mainstream of modern solid state physics in high magnetic fields. Nuclear magnetic resonance has greatly benefited from the development of high field magnets, obtaining high levels of resolution and sensitivity. One chapter in this volume is dedicated to NMR in solids using the highest fields presently available for this purpose. In the comprehensive chapter on biological systems, NMR is only one of many methods used to study systems related to living organisms. Then, there is a chapter on plasma physics 
where once there was great hope to achieve fusion by using very strong magnetic fields. Although emphasis has now shifted to very large toroidal steady-state devices, pulsed fusion with very strong magnetic fields may turn out to be a viable alternative to obtain fusion energy in smaller machines. The final chapter is another absolute highlight; it deals with the extremely high fields that have been discovered in the universe. This also provides an excellent insight into related theoretical considerations.

Each chapter provides a tutorial introduction followed by an in-depth discussion of recent experiments and theory with a view to future developments. We hope that these volumes will be useful as a stimulus as well as a reference tool for researchers and engineers working with high magnetic fields, and for students who want to become familiar with this field of research.

Volume 1 contains a survey of magnet laboratories. Since it was published two years ago, the addresses of several laboratories have changed, and web-sites have been added. An update on the addresses is given in the appendix. 